\title{
PENGARUH FREKUENSI PENYEMPROTAN DAN KONSENTRASI PUPUK ORGANIK CAIR PADA PERTUMBUHAN DAN PRODUKSI TANAMAN TOMAT (Lycopersicum esculentum Mill.)
}

\author{
Pipit Kinasih, Darwin Pangaribuan, Muhammad Syamsoel Hadi \& Yohannes Cahya Ginting \\ Jurusan Agroteknologi, Fakultas Pertanian Universitas Lampung \\ J1. Prof. Soemantri Brodjonegoro, No. 1, Bandar Lampung 35145 \\ E-mail: p.kinasih@gmail.com
}

\begin{abstract}
ABSTRAK
Penelitian ini bertujuan untuk mengetahui pengaruh frekuensi penyemprotan pupuk organik cair pada pertumbuhan dan produksi tanaman tomat, mengetahui pengaruh pemberian konsentrasi pupuk organik cair pada pertumbuhan dan produksi tanaman tomat, dan mengetahui interaksi antara frekuensi penyemprotan dan pemberian konsentrasi pupuk organik cair pada pertumbuhan dan produksi tanaman tomat. Penelitian ini dilaksanakan di Desa Jatimulyo Kecamatan Jatiagung Kabupaten Lampung Selatan dari bulan Juni sampai dengan bulan Oktober 2012. Rancangan percobaan yang digunakan adalah rancangan kelompok teracak sempurna (RKTS) yang disusun secara faktorial $(3 \times 3)$ dengan tiga ulangan. Faktor pertama adalah frekuensi penyempotan pupuk organik cair yang terdiri dari tiga taraf yaitu empat hari sekali, tujuh hari sekali, dan sepuluh hari sekali. Faktor kedua adalah konsentrasi pupuk oganik cair yang terdiri dari $1 \mathrm{ml} \mathrm{l}^{-1}$ air, $5 \mathrm{ml} \mathrm{l}^{-1}$ air dan $9 \mathrm{ml} \mathrm{l}^{-1}$ air. Hasil penelitian menunjukkan bahwa frekuensi penyemprotan pupuk organik cair tidak memberikan pengaruh terhadap semua variabel pertumbuhan dan produksi tanaman tomat, pemberian pupuk organik cair dengan konsentrasi $5 \mathrm{ml} \mathrm{l}^{-1}$ air lebih meningkatkan bobot buah per tanaman, bobot buah per petak, jumlah buah per tanaman, dan jumlah buah per petak, dan tidak terdapat interaksi antara frekuensi penyemprotan dan pemberian konsentrasi pupuk organik cair terhadap variabel pertumbuhan dan produksi tanaman tomat.
\end{abstract}

Kata kunci : Frekuensi penyemprotan, konsentrasi, tomat.

\section{PENDAHULUAN}

Tomat (Lycopersicum esculentum Mill.) yang merupakan famili dari Solanaceae adalah salah satu tanaman sayuran terpenting di Indonesia. Buah tomat yang masak banyak digemari orang karena rasanya segar, enak, dan sedikit masam. Berdasarkan data Badan Pusat Statistik (2012), produksi tomat di Indonesia pada tahun 2011 sebesar $954.046 \mathrm{t}$ dengan luas lahan 53.088 ha dan hasil rata-rata sebesar $16,65 \mathrm{tha}^{-1}$. Hasil tersebut masih sangat rendah dibandingkan dengan potensi tanaman tomat yang mampu mencapai hasil 50 sampai 70 t ha $^{-1}$ tahun (Redaksi Agromedia, 2007).

Semakin bertambahnya jumlah penduduk di Indonesia, maka permintaan akan buah tomat akan semakin meningkat pula. Rendahnya produktivitas tanaman tomat karena beberapa hal, antara lain penggunaan varietas yang tidak sesuai, jenis dan dosis atau konsentrasi pupuk yang tidak tepat, serta waktu dan frekuensi pemupukan yang tidak tepat. Salah satu upaya untuk meningkatkan pertumbuhan dan produksi buah tomat adalah dengan cara pemupukan. Pemupukan yang baik merupakan menambah unsur hara makro dan mikro yang baik dan seimbang ke dalam tanah (Wiryanta, 2002).
Pemberian pupuk organik cair harus memperhatikan konsentrasi yang diaplikasikan terhadap tanaman. Dari beberapa penelitian menunjukkan bahwa pemberian pupuk organik cair melalui daun memberikan pertumbuhan dan hasil tanaman yang lebih baik daripada pemberian melalui tanah (Hanolo, 1997). Menurut Rizqiani et al. (2007), pupuk organik cair umumnya mengandung unsur hara makro dan mikro cukup lengkap, selain itu pupuk organik cair juga mudah larut dalam air sehingga kemungkinan dengan cepat dapat diserap oleh tanaman. Hal ini merupakan sifat baik dari pupuk organik cair yang diaplikasikan melalui daun, karena efeknya akan cepat terlihat. Pemakaian pupuk daun yang banyak mengandung hara mikro dimaksudkan untuk mengimbangi pemakaian pupuk anorganik yang diberikan lewat akar karena pupuk anorganik memiliki kekurangan, yaitu sangat sedikit ataupun hampir tidak mengandung unsur hara mikro (Lingga dan Marsono, 2001).

Berdasarkan uraian diatas telah dilakukan penelitian dengan judul Pengaruh Frekuensi Penyemprotan dan Konsentrasi Pupuk Organik Cair pada Pertumbuhan dan Produksi Tanaman Tomat. Tujuan dari penelitian ini untuk mengetahui frekuensi penyemprotan, konsentrasi, serta interaksi antara 
frekuensi penyemprotan dan konsentrasi pupuk organik cair untuk pertumbuhan dan produksi tomat.

\section{BAHAN DAN METODE}

Penelitian ini dilaksanakan di Desa Jatimulyo Kecamatan Jatiagung Kabupaten Lampung Selatan dari bulan Juni sampai dengan bulan Oktober 2012. Analisis tanah dilakukan di BPTP laboratorium Teknis Natar, Lampung Selatan. Bahan yang digunakan dalam penelitian ini adalah benih tomat varietas Ratna yang diproduksi oleh PT East West Seed Indonesia, pupuk organik cair POMI yang diproduksi oleh PT Indo Acidatama, pupuk kandang sapi, kapur, pestisida, dan fungisida. Sedangkan alat yang digunakan adalah cangkul, kored, golok, meteran, sprayer 2 liter, gembor, cutter, gunting, plastik, ajir bambu, tali rafia, label, alat tulis, timbangan, oven dan jangka sorong.

Rancangan yang digunakan yaitu rancangan kelompok teracak sempurna (RKTS) yang disusun secara faktorial $(3 \times 3)$ dengan tiga ulangan. Faktor pertama adalah frekuensi penyempotan pupuk organik cair (s) yang terdiri dari tiga taraf, yaitu empat hari sekali $\left(\mathrm{s}_{1}\right)$, tujuh hari sekali $\left(\mathrm{s}_{2}\right)$, dan sepuluh hari sekali $\left(\mathrm{s}_{3}\right)$. Sedangkan faktor kedua adalah konsentrasi pupuk oganik cair (p), terdiri dari $1 \mathrm{ml} \mathrm{l}^{-1}$ air $\left(\mathrm{p}_{1}\right), 5 \mathrm{ml} \mathrm{l}^{-1}$ air $\left(\mathrm{p}_{2}\right)$, dan $9 \mathrm{ml} \mathrm{l}^{-1}$ air $\left(\mathrm{p}_{3}\right)$. Setiap kombinasi perlakuan diulang tiga kali. Analisis data dilakukan dengan sidik ragam dilanjutkan dengan uji Beda Nyata Terkecil (BNT) pada taraf $5 \%$.

Pelaksanaan Penelitian dimulai dengan persiapan lahan. Sebelum bibit tomat ditanam, dilakukan pengolahan tanah terlebih dahulu. Pengolahan tanah pertama dilakukan dengan menggunakan bajak yang ditarik oleh tenaga hewan sedalam lapisan olah tanah. Pengolahan selanjutnya dikerjakan menggunakan cangkul agar bongkahan tanah hasil pengolahan pertama menjadi remah.

Setelah tanah diolah, dilakukan pengapuran pada lahan percobaan menggunakan kapur dolomit. Dolomit diaplikasikan dengan cara ditabur di atas tanah, kemudian tanah dicangkul kembali agar tanah dan dolomit tercampur dengan rata. Sebelum dilakukan penyemaian perlu dilakukan pemilihan benih yang baik untuk mengurangi persentase kegagalan perkecambahan. Pemilihan dilakukan dengan merendam benih tomat di dalam air \pm 20 menit, kemudian dipilih benih yang tenggelam.

Pemasangan mulsa plastik hitam perak dilakukan setelah lahan selesai diolah. Mulsa dipasang ketika matahari sedang bersinar terik, sehingga mulsa sudah memuai dan akan menutup rapat seluruh bagian bedengan. Bibit tomat yang akan ditanam di lahan dipilih yang baik, yaitu pertumbuhannya tegar, warna daun hijau, tidak cacat/terkena hama penyakit. Bibit tomat ditanam tepat di lubang tanam dengan jarak $(50 \times 50) \mathrm{cm}$.

Aplikasi pupuk organik cair dilakukan dengan cara disemprotkan ke arah tubuh tanaman terutama bagian daun dan pangkal batang tanaman sampai terlihat basah. Penyemprotan pupuk organik cair pada setiap petak penelitian disesuaikan dengan dan frekuensi dan konsentrasi perlakuan. Pemeliharaan tanaman meliputi penyiraman, pengajiran, pengendalian gulma, dan pengendalian hama dan penyakit.

Pengamatan penelitian ini adalah tinggi tanaman, bobot segar dan bobot kering tanaman, bobot per buah, bobot buah per tanaman, bobot buah per petak, jumlah buah per tanaman, jumlah buah per petak, dan diameter buah. Tinggi tanaman diketahui dengan cara mengukur tinggi tanaman sampel dari pangkal batang sampai titik tumbuh tertinggi. Bobot segar tanaman dihitung dengan cara menimbang seluruh bagian tanaman yang meliputi akar, batang, daun, dan buah. Bobot kering tanaman dihitung dengan cara menimbang tanaman yang sudah dikeringkan di oven pada suhu $80^{\circ} \mathrm{C}$ selama kurang lebih 2 hari sampai berat kering yang dihasilkan konstan. Bobot per buah dihitung dengan cara menimbang sampel buah yang diambil secara acak. Bobot buah per tanaman dihitung dengan cara menimbang bobot buah per tanaman mulai dari panen pertama hingga panen kelima. Bobot buah per petak dihitung dengan cara menimbang bobot keseluruhan buah yang masak dari petak percobaan mulai dari panen pertama hingga panen kelima. Jumlah buah per tanaman dihitung dengan cara menghitung jumlah buah hasil panen pertama hingga panen kelima pada setiap tanaman. Jumlah buah per petak dihitung dengan cara menghitung jumlah buah hasil panen pertama hingga panen kelima pada setiap petak percobaan. Diameter buah diukur dengan cara mengukur buah menggunakan jangka sorong.

\section{HASIL DAN PEMBAHASAN}

Hasil penelitian menunjukkan bahwa frekuensi penyemprotan pupuk organik cair tidak memberikan pengaruh pada semua variabel pengamatan, sedangkan pemberian konsentrasi pupuk organik cair berpengaruh pada variabel bobot buah per tanaman, bobot buah per petak, jumlah buah per tanaman, dan jumlah buah per petak. Interaksi antara frekuensi penyemprotan dan pemberian konsentrasi pupuk organik cair tidak memberikan pengaruh terhadap semua variabel yang diamati (Tabel 1). Frekuensi penyemprotan, konsentrasi pupuk organik cair, dan interaksi antara kedua perlakuan 
Tabel 1. Rekapitulasi hasil analisis ragam pengaruh frekuensi penyemprotan dan konsentrasi pupuk organik cair pada pertumbuhan dan produksi tanaman tomat.

\begin{tabular}{lccc}
\hline \multirow{2}{*}{ Variabel Pengamatan } & \multicolumn{2}{c}{ Perlakuan } \\
\cline { 2 - 4 } & Frekuensi penyemprotan $(\mathrm{S})$ & Konsentrasi $(\mathrm{P})$ & $\mathrm{S} \mathrm{x} \mathrm{P}$ \\
\hline Tinggi tanaman & tn & tn & tn \\
Bobot segar tanaman & tn & tn & tn \\
Bobot kering tanaman & tn & tn & tn \\
Bobot per buah & tn & $*$ & tn \\
Bobot buah per tanaman & tn & $*$ & tn \\
Bobot buah per petak & tn & $*$ & tn \\
Jumlah buah per tanaman & tn & $*$ & tn \\
Jumlah buah per petak & tn & tn & tn \\
Diameter buah & tn & & tn \\
\hline
\end{tabular}

Keterangan: $\operatorname{tn}=$ tidak nyata, ${ }^{*}=$ nyata pada $\alpha_{0,05}, * *=$ nyata pada $\alpha_{0,05}$.

tidak berpengaruh terhadap tinggi tanaman tomat. Ratarata tinggi tanaman tomat yaitu $60,65 \mathrm{~cm}$ (tabel 2). Frekuensi penyemprotan, konsentrasi pupuk organik cair, dan interaksi antara kedua perlakuan tidak berpengaruh terhadap bobot segar tanaman tomat. Rata-rata bobot segar tanaman tomat yaitu 98,85 g (Tabel 2).

Frekuensi penyemprotan, konsentrasi pupuk organik cair, dan interaksi antara kedua perlakuan tidak berpengaruh terhadap bobot kering tanaman tomat. Rata-rata bobot kering tanaman tomat yaitu 42,06 g (Tabel 2). Frekuensi penyemprotan, konsentrasi pupuk organik cair, dan interaksi antara kedua perlakuan tidak berpengaruh terhadap bobot per buah tomat. Rata-rata bobot per buah tomat yaitu 22,43 g (Tabel 2). Frekuensi penyemprotan dan interaksi antara kedua perlakuan tidak berpengaruh, namun pemberian konsentrasi pupuk organik cair mampu meningkatkan bobot buah per tanaman. Pemberian konsentrasi pupuk organik cair 5 $\mathrm{ml} \mathrm{l}^{-1}$ air menghasilkan bobot buah per tanaman tertinggi yaitu 105,67 g (Tabel 3).

Frekuensi penyemprotan dan interaksi antara kedua perlakuan tidak berpengaruh, namun pemberian konsentrasi pupuk organik cair mampu meningkatkan bobot buah per petak. Pemberian konsentrasi pupuk organik cair $5 \mathrm{ml} \mathrm{l}^{-1}$ air menghasilkan bobot buah per petak tertinggi yaitu 1267,98 g (Tabel 3). Frekuensi penyemprotan dan interaksi antara kedua perlakuan tidak berpengaruh, namun pemberian konsentrasi pupuk organik cair mampu meningkatkan jumlah buah per tanaman. Pemberian konsentrasi pupuk organik cair 5 $\mathrm{ml} \mathrm{l}^{-1}$ air menghasilkan jumlah buah per tanaman tertinggi yaitu 4,84 buah (tabel 3 ). Frekuensi penyemprotan dan interaksi antara kedua perlakuan tidak berpengaruh, namun pemberian konsentrasi pupuk organik cair mampu meningkatkan jumlah buah per petak Pemberian konsentrasi pupuk organik cair $5 \mathrm{ml} \mathrm{l}^{-1}$ air menghasilkan jumlah buah per petak tertinggi yaitu 58,11 buah (Tabel $3)$.

Frekuensi penyemprotan, konsentrasi pupuk organik cair, dan interaksi antara kedua perlakuan tidak berpengaruh terhadap diameter buah tomat. Rata-rata diameter buah tomat yaitu $2,83 \mathrm{~cm}$ (Tabel 2).

Hasil penelitian menunjukkan bahwa frekuensi penyemprotan pupuk organik cair tidak berpengaruh terhadap semua variabel pengamatan. Hal ini diduga karena interval waktu penyemprotan pupuk organik cair yang terlalu jauh yaitu empat hari sekali, tujuh hari sekali, dan sepuluh hari sekali, sehingga memberikan pengaruh yang tidak nyata. Menurut hasil penelitian Rizqiani et al. (2007), frekuensi pemberian pupuk organik cair dua kali aplikasi penyemprotan mempunyai pengaruh yang sama dengan frekuensi pemberian pupuk organik cair tiga kali dan empat kali aplikasi penyemprotan terhadap semua variabel pengamatan pada tanaman buncis. Seperti dikemukakan oleh Lingga dan Marsono (2001), bahwa dalam penyemprotan pupuk daun ada beberapa hal yang perlu diperhatikan yaitu selain jenis pupuk daun yang digunakan, kandungan hara pupuk daun dan konsentrasi larutan yang diberikan, juga waktu penyemprotan.

Hasil penelitian menunjukkan bahwa pemberian konsentrasi pupuk organik cair sebanyak $5 \mathrm{ml} \mathrm{l}^{-1}$ air lebih meningkatkan bobot buah per tanaman, bobot buah per petak, jumlah buah per tanaman, dan jumlah buah per petak. Hal ini diduga dengan konsentrasi pupuk organik cair sebanyak $5 \mathrm{ml} \mathrm{l}^{-1}$ air, unsur hara makro dan mikro yang dibutuhkan tanaman telah sesuai jumlahnya yang sesuai dengan konsentrasi anjuran dalam label POMI (2007) di samping dengan pemakaian pupuk kandang sapi sebagai pupuk dasar. Selain unsur hara makro N, $\mathrm{P}, \mathrm{K}, \mathrm{Ca}$, dan $\mathrm{Mg}$, pupuk organik cair yang digunakan dalam penelitian ini juga mengandung unsur hara mikro, 
Tabel 2. Pengaruh penyemprotan pupuk organik cair dan konsentrasi pupuk organik cair terhadap tinggi tanaman $(\mathrm{cm})$, bobot segar tanaman $(\mathrm{g})$, bobot kering tanaman $(\mathrm{g})$, bobot per buah $(\mathrm{g})$, dan diameter buah $(\mathrm{cm})$.

\begin{tabular}{cccccc}
\hline & \multicolumn{5}{c}{ Nilai Rata-rata } \\
\cline { 2 - 6 } Perlakuan & $\begin{array}{c}\text { Tinggi tanaman } \\
(\mathrm{cm})\end{array}$ & $\begin{array}{c}\text { Bobot segar } \\
\text { tanaman }(\mathrm{g})\end{array}$ & $\begin{array}{c}\text { Bobot kering } \\
\text { tanaman }(\mathrm{g})\end{array}$ & $\begin{array}{c}\text { Bobot per } \\
\text { buah }(\mathrm{g})\end{array}$ & $\begin{array}{c}\text { Diameter } \\
\text { buah }(\mathrm{cm})\end{array}$ \\
\hline $\mathrm{s}_{1} \mathrm{p}_{1}$ & 59,80 & 104,06 & 43,80 & 19,30 & 2,69 \\
$\mathrm{~s}_{1} \mathrm{p}_{2}$ & 62,40 & 100,94 & 42,80 & 22,57 & 2,87 \\
$\mathrm{~s}_{1} \mathrm{p}_{3}$ & 60,07 & 99,48 & 42,18 & 23,49 & 2,95 \\
$\mathrm{~s}_{2} \mathrm{p}_{1}$ & 63,60 & 107,87 & 46,10 & 22,36 & 2,82 \\
$\mathrm{~s}_{2} \mathrm{p}_{2}$ & 55,81 & 105,03 & 44,55 & 24,14 & 2,84 \\
$\mathrm{~s}_{2} \mathrm{p}_{3}$ & 63,93 & 92,62 & 39,58 & 21,91 & 2,84 \\
$\mathrm{~s}_{3} \mathrm{p}_{1}$ & 63,59 & 95,25 & 40,71 & 23,72 & 2,88 \\
$\mathrm{~s}_{3} \mathrm{p}_{2}$ & 57,73 & 92,11 & 39,36 & 21,81 & 2,74 \\
$\mathrm{~s}_{3} \mathrm{p}_{3}$ & 58,97 & 92,25 & 39,42 & 22,61 & 2,83 \\
\hline Rata-rata & 60,65 & 98,85 & 42,06 & 22,43 & 2,83 \\
\hline
\end{tabular}

Tabel 3. Pengaruh pemberian konsentrasi pupuk organik cair terhadap bobot buah per tanaman (g), bobot buah per petak (g), jumlah buah per tanaman (buah), dan jumlah buah per petak (buah).

\begin{tabular}{ccccc}
\hline $\begin{array}{c}\text { Konsentrasi pupuk } \\
\text { organik cair }\end{array}$ & $\begin{array}{c}\text { Bobot buah per } \\
\operatorname{tanaman}(\mathrm{g})\end{array}$ & $\begin{array}{c}\text { Bobot buah per } \\
\text { petak }(\mathrm{g})\end{array}$ & $\begin{array}{c}\text { Jumlah buah per } \\
\text { tanaman (buah) }\end{array}$ & $\begin{array}{c}\text { Jumlah buah per } \\
\text { petak (buah) }\end{array}$ \\
\hline $1 \mathrm{ml} \mathrm{l}^{-1}$ air & $98,39 \mathrm{ab}$ & $1180,70 \mathrm{ab}$ & $4,51 \mathrm{ab}$ & $54,11 \mathrm{ab}$ \\
$5 \mathrm{ml} \mathrm{l}^{-1}$ air & $105,67 \mathrm{~b}$ & $1267,98 \mathrm{~b}$ & $4,84 \mathrm{~b}$ & $58,11 \mathrm{~b}$ \\
$9 \mathrm{ml} \mathrm{l}^{-1}$ air & $91,93 \mathrm{a}$ & $1103,12 \mathrm{a}$ & $4,19 \mathrm{a}$ & $50,33 \mathrm{a}$ \\
\hline $\mathrm{BNT}_{0,05}$ & 10,43 & 129,12 & 0,48 & 5,75 \\
\hline
\end{tabular}

Keterangan: Angka yang diikuti oleh huruf yang sama pada kolom yang sama tidak berbeda nyata berdasarkan uji BNT pada $\alpha_{0,05}$.

seperti unsur hara $\mathrm{B}, \mathrm{Cu}, \mathrm{Fe}$, dan Mo (Label POMI, 2007), yang berfungsi merangsang pertumbuhan generatif pada tanaman tomat

Menurut hasil penelitian Rahmi dan Jumiati (2007), pemberian pupuk organik cair super ACI dengan konsentrasi 1,43 $\mathrm{ml} \mathrm{l}^{-1}$ air lebih baik daripada konsentrasi $0,71 \mathrm{ml} \mathrm{l}^{-1}$ air dan $2,15 \mathrm{ml} \mathrm{l}^{-1}$ air dalam menghasilkan tinggi tanaman, saat keluar bunga jantan dan bunga betina serta panen yang lebih cepat, komponen tongkol yang lebih baik dan produksi tongkol yang lebih tinggi pada tanaman jagung manis.

Berdasarkan hasil penelitian ini pemberian pupuk organik cair sebanyak $5 \mathrm{ml} \mathrm{l}^{-1}$ air lebih meningkatkan hasil tanaman tomat, namun dengan pemberian konsentrasi sebanyak $9 \mathrm{ml} \mathrm{l}^{-1}$ air cenderung menurunkan hasil. Menurut Lingga dan Marsono (2001), agar pemberian pupuk daun dapat memberikan hasil sesuai dengan yang diharapkan, maka konsentrasi yang diberikan tidak melebihi konsentrasi yang dianjurkan. Konsentrasi anjuran dalam label POMI yaitu $5 \mathrm{ml} \mathrm{l}^{-1}$ air. Pupuk organik cair POMI berisi mikrobia pengurai bahan organik, seperti Azotobacter, Azospirillum,
Aspergillus, Bacillus, dan Pseudomonas, yang berfungsi sebagai penambat $\mathrm{N}$, pelarut $\mathrm{P}$, pelarut $\mathrm{K}$, serta penghasil fitohormon, vitamin, asam amino, dan zat anti penyakit tanaman. Pupuk organik cair POMI juga mengandung unsur hara makro $(\mathrm{N}, \mathrm{P}, \mathrm{K}, \mathrm{Ca}$, dan $\mathrm{Mg}$ ) dan unsur hara mikro lengkap (unsur dominan pada $\mathrm{B}$, $\mathrm{Cu}, \mathrm{Fe}$, dan $\mathrm{Mo}$ ).

Menurut Lingga dan Marsono (2001), pupuk organik cair diberikan pada tanaman dengan cara disemprotkan pada tanaman. Unsur hara dalam bentuk larutan yang diberikan melalui daun akan masuk ke dalam tanaman melalui stomata. Pada saat stomata membuka dan gas $\mathrm{CO}_{2}$ dapat masuk melalui stomata. Pada saat yang bersamaan dengan masuknya $\mathrm{CO}_{2}$, larutan pupuk organik cair disemprotkan pada daun sehingga larutan bisa masuk melalui stomata. Selanjutnya bahan terlarut dan molekul organik yang terbentuk dalam proses fotosintesis akan dipindahkan atau ditranslokasikan melalui floem (jaringan pengangkut).

Hasil penelitian tidak menunjukkan adanya interaksi antara frekuensi penyemprotan dan pemberian 
konsentrasi pupuk organik cair terhadap tanaman tomat. Hal ini diduga interval waktu penyemprotan pupuk organik cair yang terlalu jauh yaitu empat hari sekali, tujuh hari sekali, dan sepuluh hari sekali dengan pemberian konsentrasi pupuk organik cair yang jumlahnya sampai melebihi konsentrasi anjuran yaitu lebih dari $5 \mathrm{ml} \mathrm{l}^{-1}$ air. Menurut Sutedjo (2008), unsur hara yang dibutuhkan oleh tanaman jika tersedia dalam jumlah yang cukup, memungkinkan tanaman untuk tumbuh dan berproduksi secara optimal.

\section{KESIMPULAN}

Berdasarkan hasil penelitian dapat disimpulkan bahwa frekuensi penyemprotan pupuk organik cair dan interaksi antara kedua faktor perlakuan tidak berpengaruh pada semua variabel pengamatan, namun pemberiankonsentrasi pupuk organik cair $5 \mathrm{ml} \mathrm{l}^{-1}$ air lebih meningkatkan bobot buah per tanaman, bobot buah per petak, jumlah buah per tanaman, dan jumlah buah per petak.

\section{DAFTAR PUSTAKA}

Badan Pusat Statistik. 2012. Luas Panen, Produksi, dan Produktivitas Tomat Menurut Provinsi, 2007 -2011. http://www.deptan.go.id/infoeksekutif/ horti/pdf-ATAP2011/LP-Tomat.pdf. Diakses pada tanggal 27 November 2012.
Hanolo, W. 1997. Tanggapan Tanaman Selada dan Sawi Terhadap Dosis dan Cara Pemberian Pupuk Cair Stimulan. J. Agrotropika 1(1):25-29.

Lingga, P. dan Marsono. 2001. Petunjuk Penggunaan Pupuk. Penebar Swadaya. Jakarta. $150 \mathrm{hlm}$.

Rahmi, A. dan Jumiati. 2007. Pengaruh Konsentrasi dan Waktu Penyemprotan Pupuk Organik Cair Super ACI terhadap Pertumbuhan dan Hasil Jagung Manis. J. Agritrop 26(3):105-109.

Redaksi Agromedia. 2007. Panduan Lengkap Budidaya Tomat. Jakarta. Agromedia Pustaka. $100 \mathrm{hlm}$.

Rizqiani, N. F., E. Ambarwati, dan N. W. Yuwono. 2007. Pengaruh Dosis dan Frekuensi Pemberian Pupuk Organik Cair terhadap Pertumbuhan dan Hasil Buncis (Phaseolus vulgaris L.) Dataran Rendah. J. Ilmu Tanah dan Lingkungan 7(1):43-53.

Wiryanta, B. T. W. 2002. Bertanam Tomat. Agromedia Pustaka. Jakarta. $101 \mathrm{hlm}$. 